\title{
DESEMPENHO DE LINHAGENS DIAPLÓIDES DE TRIGO OBTIDAS VIA CULTURA DE ANTERAS QUANTO À TOLERÂNCIA AO ALUMínio, PRODUÇÃo DE GRÃos E ALTURA DE PLANTA ${ }^{(1)}$
}

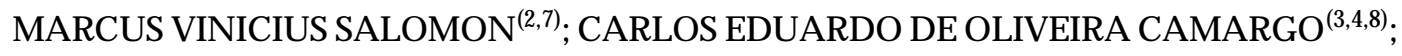 \\ ANTONIO WILSON PENTEADO FERREIRA FILHO ${ }^{(4)}$, ARMANDO PETTINELLI JÚNIOR ${ }^{(5)}$; \\ JAIRO LOPES DE CASTRO(6)
}

\begin{abstract}
RESUMO
Avaliaram-se 18 linhagens diaplóides de trigo, obtidas via cultura de anteras in vitro oriundas de híbridos $\mathrm{F}_{1}$, e dois cultivares IAC-24 e IAC-289, nos anos de 1999 e 2000, em dois locais do Estado de São Paulo: Capão Bonito (solo ácido, sem aplicação de calcário e em condição de sequeiro) e em Tatuí (solo ácido, com aplicação de calcário e em condição de irrigação por aspersão). Em cada experimento avaliaram-se a produção de grãos e a altura das plantas. Foi, também, avaliada a tolerância à toxicidade de alumínio, empregando-se soluções nutritivas contendo 0, 2, 4, 6, 8 e $10 \mathrm{mg} . \mathrm{L}^{-1}$, em condição de laboratório. As linhagens diaplóides consideradas mostraram grande variabilidade para os caracteres agronômicos avaliados. Destacaram-se quanto à produção de grãos, considerando a média dos experimentos de Capão Bonito, as linhagens 9 (MRL"S" / BUC"S" / / BUC"S" /3/ IAC-24), 4 (PF70402/ALD“S" / / PAT72160/ALD“S" / 3/PEW"S" /4/OPATA/5/IAC-60) e 3 (TEPOCA/IAC-24). Em Tatuí, considerando-se a média dos dois anos, destacaram-se quanto à produção de grãos as linhagens 4 e 5 , oriundas do mesmo cruzamento. A linhagem 13 (JUN/GEN//IAC-24) apresentou as plantas mais baixas nos quatro experimentos. Todos os genótipos, com exceção da cultivar IAC-289 e da linhagem 13, foram considerados tolerantes a $10 \mathrm{mg}$. $\mathrm{L}^{-1}$ de $\mathrm{Al}^{3+}$, quando avaliados em soluções nutritivas. Os resultados reforçam a possibilidade de selecionar os genótipos tolerantes ao alumínio, em condição de laboratório, antes que sejam avaliados em campo, em solo ácido, tornando o processo de obtenção de linhagens tolerantes mais eficiente.
\end{abstract}

Palavras-chave: trigo, tolerância ao alumínio, produção de grãos, altura das plantas, linhagens diaplóides.

\author{
ABSTRACT \\ PERFORMANCE OF DIHAPLOID WHEAT LINES OBTAINED VIA ANTHER CULTURE IN \\ RELATION TO THE ALUMINUM TOLERANCE, GRAIN YIELD AND PLANT HEIGHT
}

Eighteen dihaploid wheat lines originated via anther culture from $\mathrm{F}_{1}$ hybrid plants and two cultivars IAC-24 and IAC-289 were evaluated in 1999 and 2000, at two locations of the State of São Paulo: Capão Bonito (acid soil without lime application and upland condition) and Tatuí (acid soil with lime application

$\left({ }^{1}\right)$ Recebido para publicação em 7 de junho de 2002 e aceito em 7 de abril de 2003.

$\left(^{2}\right)$ Pós-graduado em Fitotecnia, ESALQ/USP,Caixa Postal 9, 13418-900 Piracicaba (SP).E-mail: salomonmv@hotmail.com

$\left({ }^{3}\right)$ Departamento de Produção Vegetal, ESALQ/USP, Piracicaba (SP)

$\left({ }^{4}\right)$ Centro de Análise e Pesquisa Tecnológica do Agronegócio de Grãos e Fibras, IAC, Caixa Postal 28, 13001-970 Campinas (SP). E-mail: ccamargo@iac.br

$\left(^{5}\right)$ Unidade de Pesquisa do Desenvolvimento de Tatuí , APTA, Caixa Postal 33, 18270-000 Tatuí (SP).

${ }^{(6)}$ Pólo Regional de Desenvolvimento Tecnológico dos Agronegócios do Sudoeste Paulista, Caixa Postal 62, 18300-970, Capão Bonito (SP).

$\left({ }^{7}\right)$ Bolsista da FAPESP.

$\left({ }^{8}\right)$ Com bolsa de produtividade em pesquisa do CNPq. 
and sprinkler irrigation condition). In each trial the genotypes were evaluated for grain yield and plant height. Aluminum toxicity tolerance was also evaluated in the laboratory in nutrient solutions containing $0,2,4,6,8$ and $10 \mathrm{mg} . \mathrm{L}^{-1}$ of aluminum. The evaluated dihaploid lines showed high variability for the considered agronomic characters. The lines 9 (MRL"S" / BUC"S" / / BUC "S" /3/IAC-24), 4 (PF70402/ ALD"S" / /PAT72160/ALD“S"/3/PEW"S"/4/OPATA/5/IAC-60) and 3 (TEPOCA/IAC-24) displayed good performance in relation to grain yield considering the means of the Capão Bonito trials. In Tatuí the lines 4 and 5 originated from the same cross showed good behaviour for grain yield taking into account the means of the trials. The line 13 (JUN/GEN//IAC-24) exhibited short plants in all trials. All genotypes, except the cultivar IAC-289 and the line 13 were considered tolerant at $10 \mathrm{mg} \cdot \mathrm{L}^{-1}$ to $\mathrm{Al}^{3+}$, in nutrient solution. The results indicated the possibility to select tolerant genotypes to aluminum toxicity in laboratory condition before they are evaluated in acid soil, making the process of obtaining tolerant lines more efficient.

Key words: wheat, aluminum tolerance, grain yield, plant height, dihaploid lines.

\section{INTRODUÇÃO}

Os solos brasileiros, na maioria, são bastante lixiviados, pobres, de elevada acidez e com freqüência possuem alta concentração de alumínio provocando toxicidade em muitas plantas cultivadas (Olmos e Camargo, 1976).

A toxicidade de alumínio é caracterizada pela inibição do alongamento da raiz, um sintoma claramente identificado em plantas superiores. Essa restrição do crescimento radicular provoca a diminuição da produção de grãos, da altura da planta e do número de perfilhos (CAMARgo e Oliveira, 1981).

A tolerância à toxicidade de alumínio é um fator importante para garantir bom desenvolvimento do sistema radicular do trigo, em solos ácidos, permitindo a obtenção de água em maiores profundidades nas épocas de seca, quando cultivares sensíveis não sobreviveriam, devido à inibição no crescimento radicular provocada pelo alumínio, além da camada superficial, quase sempre corrigida pela prática da calagem (Alves et al., 1988; CAmargo e Oliveira, 1981 e RosA et al., 1994).

A alternativa para diminuir os problemas da toxicidade de alumínio e a conseqüente redução na produtividade das culturas é o melhoramento genético visando à obtenção de cultivares com elevada tolerância a altos níveis de alumínio (BRAUNER e SARruge, 1980; Camargo et al., 1990, 1991b e Rosa et al., 1994).

Uma das técnicas empregadas para o estudo da reação de cultivares de trigo ao alumínio tóxico baseia-se na paralisação irreversível do meristema das raízes primárias de trigo em estádio de plântula, utilizando-se soluções nutritivas (CAMARGo e Oliveira, 1981 e CAMARGO et al., 1990, 1991a).

O programa de melhoramento genético do trigo, no Instituto Agronômico (IAC), em Campinas, visa à obtenção de cultivares com maior produtividade, resistência às doenças e tolerância à toxicidade de alumínio. A obtenção de cultivares, no IAC, até recentemente, tem sido embasada nos métodos tradicionais de melhoramento a partir de cruzamentos. Entretanto, é reconhecido que ferramentas como a indução de mutação e outras biotecnologias, ou seja, a obtenção de linhagens diaplóides com base em duplicação cromossômica de plantas haplóides, originárias de cultura de anteras in vitro de plantas híbridas, em geração $F_{1}$, podem contribuir para reduzir tempo e custos e melhorar a eficiência na seleção (RAmOs et al., 1994, CAMARGO et al., 1999).

A técnica de cultura de anteras, visando à produção de diaplóides, vem sendo amplamente empregada na obtenção de novas cultivares em várias plantas de interesse agronômico.

Na China, ainda na década de 70, foram desenvolvidas as primeiras cultivares de fumo, arroz e trigo, obtidas mediante o cultivo de anteras (MORAESFERNANDES et al., 1999). No Brasil, a cultivar de trigo BR-43 foi produzida por meio desse método (CAETANO e MoraEs-FernANDES, 1992).

Através da avaliação preliminar, em condição de campo, as linhagens diaplóides mostraram grande variabilidade para os caracteres agronômicos como altura de planta, produção de grãos, massa de cem grãos, acamamento e resistência à ferrugem-dafolha (CAMARGO et al., 1999), também diferiram quanto à tolerância a toxicidade de alumínio, quando avaliadas em solução nutritiva, em laboratório (CAMARGO et al., 1999; RAmos et al., 2000; SALOMON et al., 2003).

O presente trabalho teve como objetivo: 1) avaliar as linhagens diaplóides de trigo, em dois locais do Estado de São Paulo, em 1999 e 2000, em relação à produção de grãos, altura da planta e tolerância à toxicidade de alumínio; 2 ) verificar a associação entre os resultados apresentados pelos genótipos em condição de campo, em solo ácido, e de laboratório em relação à tolerância à toxicidade de alumínio. 


\section{MATERIAL E MÉTODOS}

Instalou-se um experimento composto de $18 \mathrm{li}$ nhagens diaplóides e duas cultivares: IAC-24 e IAC-289, atualmente recomendadas para cultivo (Campinas, 2002), em dois locais no Estado de São Paulo, em 1999 e 2000. Adotou-se o delineamento estatístico de blocos ao acaso, com quatro repetições. Esse experimento constituiu-se de 80 parcelas, cada uma com seis linhas de $3 \mathrm{~m}$ de comprimento, espaçadas de $0,20 \mathrm{~m}$.

A genealogia dos genótipos avaliados é apresentada no quadro 1 . Os experimentos foram instalados no Pólo Regional de Desenvolvimento Tecnológico dos Agronegócios do Sudoeste Paulista, em Capão Bonito (Zona tritícola B), em solo ácido sem aplicação de calcário e em condição de sequeiro e na Unidade de Pesquisa do Desenvolvimento de Tatuí
(Zona tritícola D), em solo ácido com aplicação de calcário e em condição de irrigação por aspersão, em 1999 e 2000.

Em cada local, retiraram-se amostras compostas dos solos, na profundidade de $0-20 \mathrm{~cm}$, visando às análises químicas efetuadas pelo Centro de Pesquisa e Desenvolvimento de Solos e Recursos Agroambientais, do Instituto Agronômico (IAC), em Campinas. A quantidade de fertilizante empregada $\left(\mathrm{N}, \mathrm{P}_{2} \mathrm{O}_{5}\right.$ e $\left.\mathrm{K}_{2} \mathrm{O}\right)$, nos diferentes locais, baseou-se nas recomendações de adubação do IAC resultantes das análises químicas do solo (RAIJ et al., 1985).

A cultivar-controle IAC-24, caracteriza-se por apresentar porte semi-anão, tolerância à toxicidade de alumínio, média exigência em fertilidade do solo (CAMPINAS, 1996), e a 'IAC-289', porte semi-anão, moderada tolerância à toxicidade de alumínio, alta exigência em fertilidade do solo (CAMPINAs, 1999).

Quadro 1. Genealogia dos genótipos avaliados no Experimento de Linhagens Diaplóides de Trigo, no Pólo Regional de Desenvolvimento Tecnológico dos Agronegócios do Sudoeste Paulista do Sudoeste Paulista (PRDTA), em Capão Bonito, e na Unidade de Pesquisa do Desenvolvimento de Tatuí, em 1999 e 2000

\begin{tabular}{|c|c|c|c|}
\hline Genótipos & N. ${ }^{o}$ da Planta & Híbrido & Genealogia \\
\hline 1 & 2460 & H.20560 & JUN / GEN / / IAC-24 \\
\hline 2 & 2461 & H.20560 & JUN / GEN / / IAC-24 \\
\hline 3 & 2462 & H.20558 & TEPOCA/IAC-24 \\
\hline 4 & 2470 & H.20977 & PF70402/ALD“S" / / PAT72160/ALD“S"/3/PEW"S" / 4/OPATA/5/IAC-60 \\
\hline 5 & 2470 & H.20977 & PF70402 / ALD“S” / / PAT72160/ALD“S”/3/PEW“S” / 4 /OPATA / 5 / IAC-60 \\
\hline 6 & 2474 & H.20976 & PF70402 / ALD“S" / / PAT72160/ALD“S" /3 / PEW"S" / 4 / OPATA / 5 / IAC-60 \\
\hline 7 & 2485 & H.20550 & TRAP1*2/ / ERP / RUSO/3/IAC-24 \\
\hline 8 & 2488 & H.20552 & PFAU / 4 / BB / GLL / / CJ / 3 / F35.70 / / KAL / 5 / VEE7 / 6 / IAC-24 \\
\hline 9 & 2501 & H.20409 & MRL"S" / BUC"S" / / BUC"S"/3/IAC-24 \\
\hline 10 & 2521 & H.20553 & CS / A.CURV / / GLEN/3/ALD/PVN/4/SUZ8/5/IAC-24 \\
\hline 11 & 2556 & H.20558 & TEPOCA/IAC- 24 \\
\hline 12 & 2557 & H.20558 & TEPOCA / IAC -24 \\
\hline 13 & 2563 & H.20560 & JUN / GEN / / IAC-24 \\
\hline 14 & 2580 & H.20976 & PF70402 / ALD“S" / / PAT72160/ALD“S" /3 / PEW“S" / 4 /OPATA/5/IAC-60 \\
\hline 15 & 2581 & H.20976 & PF70402 / ALD“S" / / PAT72160/ALD“S” /3 / PEW“S" / 4 /OPATA / 5 / IAC-60 \\
\hline 16 & 2582 & H.20976 & PF70402 / ALD“S” / / PAT72160/ALD“S" / 3 / PEW“S” / 4 /OPATA / 5 / IAC-60 \\
\hline 17 & 2605 & H.20526 & FURY-KEN /SLM / / ALDAN / 4 / PAT10 / ALD / / PAT72300/3 / PVN / 4 / AC-24 \\
\hline 18 & 2626 & H.20558 & TEPOCA/IAC-24 \\
\hline 19 & - & - & IAS-51 / IRN597-70 (IAC-24) \\
\hline 20 & - & - & KVZ/BUHO"S" / / KAL/BLUEBIRD (IAC-289) \\
\hline
\end{tabular}


Efetuou-se a semeadura utilizando 80 sementes por metro linear de sulco (CAmPINAs, 2002), o que equivale a 1.440 sementes por parcela, com área útil de $3,6 \mathrm{~m}^{2}$. Nesse experimento, realizaram-se as seguintes avaliações:

Altura da planta: medida, em centímetros, no campo, em três pontos de cada parcela, na época da maturação, do nível do solo ao ápice da espiga, excluindo-se as aristas.

Produção de grãos: considerando-se a produção total de grãos de cada parcela, transformada em kg.ha ${ }^{-1}$.

Os dados de produção de grãos e altura da planta obtidos no experimento instalado nos dois locais, em 1999 e 2000, foram submetidos à análise da variância, utilizando-se o teste $\mathrm{F}$, a 5\%, para testar efeitos de genótipos.

Analisaram-se as variâncias conjuntas das duas características avaliadas para cada local, considerando-se em conjunto os dois anos, detectando-se, pelo teste $\mathrm{F}$, a $5 \%$, as significâncias dos efeitos de genótipos, de anos e da interação genótipos $\mathrm{x}$ anos. Este procedimento foi adotado considerando-se a diferença marcante entre os dois locais quanto à fertilidade do solo e às condições de cultivo.

Empregou-se o teste de Tukey a 5\%, para a comparação das médias de genótipos em cada experimento, independentemente de local e ano, e na média de cada local, considerando-se em conjunto os dois anos de avaliação.

A tolerância à toxicidade de alumínio dos genótipos estudados, foi avaliada em solução nutritiva contendo $0,2,4,6$, 8 e $10 \mathrm{mg} . \mathrm{L}^{-1}$ de alumínio, em condição de laboratório, empregando-se como controle as cultivares BH-1146 e Anahuac, tolerante e sensível ao alumínio, respectivamente. O método adotado para essas avaliações foi o descrito por CAMARGO e OLIVEIRA (1981).

O comprimento médio da raiz de cada genótipo foi representado pela média das dez plântulas avaliadas em cada concentração, nas cinco repetições.

Além das análises da variância, realizaramse correlações simples entre produção de grãos e altura da planta, produção de grãos e comprimento médio das raízes nas diferentes concentrações de alumínio e entre altura da planta e comprimento médio das raízes nas diferentes concentrações de alumínio, considerando-se os dados dos vinte genótipos estudados. Nessas correlações, utilizaram-se as médias de cada um dos vinte genótipos, considerando-se em conjunto os dois anos em cada local.

\section{RESULTADOS E DISCUSSÃO}

As diferentes condições de cultivo (Capão Bonito e Tatuí) influenciaram as características avaliadas. Os genótipos cultivados em Capão Bonito mostraram médias de produção de grãos mais baixas quando comparadas às de Tatuí, possivelmente em função da menor fertilidade e dos elevados teores de alumínio no solo. Provavelmente, a condição de sequeiro, em Capão Bonito, foi outro fator importante contribuindo para essa diferença.

Em Capão Bonito, em 2000, ocorreu menor disponibilidade hídrica, em vista do menor volume de chuvas no período inicial de cultivo. Esse fato obrigou o uso da irrigação por aspersão, para que as plantas emergissem, mesmo considerando que, nesse local, o experimento seria desenvolvido em condição de sequeiro (sem irrigação). Além da seca no início da cultura e geadas em julho, ocorreram chuvas na época de maturação e colheita, afetando negativamente o rendimento da cultura (Figura 1).

Em Tatuí, em julho de 2000, registraram-se, no abrigo meteorológico, temperaturas mínimas extremamente baixas durante as noites de $17\left(-1,4{ }^{\circ} \mathrm{C}\right), 18$ $\left(-1,2{ }^{\circ} \mathrm{C}\right), 21\left(-2,0^{\circ} \mathrm{C}\right)$ e $22\left(-1,8^{\circ} \mathrm{C}\right)$ (Figura 2). Segundo Mота (1982), a temperatura de $-2,0{ }^{\circ} \mathrm{C}$, na folha, seria o limite abaixo do qual os danos provocados pela geada já se fariam sentir na cultura do trigo, em vista de disfunções provocadas nos processos metabólicos da planta. Nesse local, em 2000, houve também ocorrência de chuvas na época da maturação, prejudicando a produção de grãos do experimento.

Os experimentos instalados em Capão Bonito, nos dois anos (Quadro 2), quando analisados em conjunto, mostraram efeitos não significativos para genótipos e significativos para anos e para a interação genótipos $\mathrm{x}$ anos. $\mathrm{O}$ efeito de anos foi provavelmente devido à deficiência hídrica no período inicial do ciclo em 2000, resultando em redução de $65,38 \%$ na produção de grãos, quando comparado ao ano anterior (Figura 1). A interação genótipos $\mathrm{x}$ anos indicou que a maioria dos genótipos avaliados apresentou comportamento diferencial para a produção de grãos em função do ano considerado (Quadro 2).

A comparação das médias de produção de grãos, em Capão Bonito, em 1999, indicou que a linhagem 4, com $2.021 \mathrm{~kg} \cdot \mathrm{ha}^{-1}$ foi a mais produtiva, diferindo, porém em kg.ha ${ }^{-1}$, somente dos genótipos 1 (1.232), 2 (1.410), 10 (969), 13 (976), 15 (1.292) e 16 (1.386). Em 2000, a linhagem 9 apresentou uma produção de $1.188 \mathrm{~kg} . h a^{-1}$, só não diferindo, em kg.ha ${ }^{-1}$, dos genótipos 3 (931), 10 (910), 15 (726), 16 (726), 18 (993) e 19 (792). 


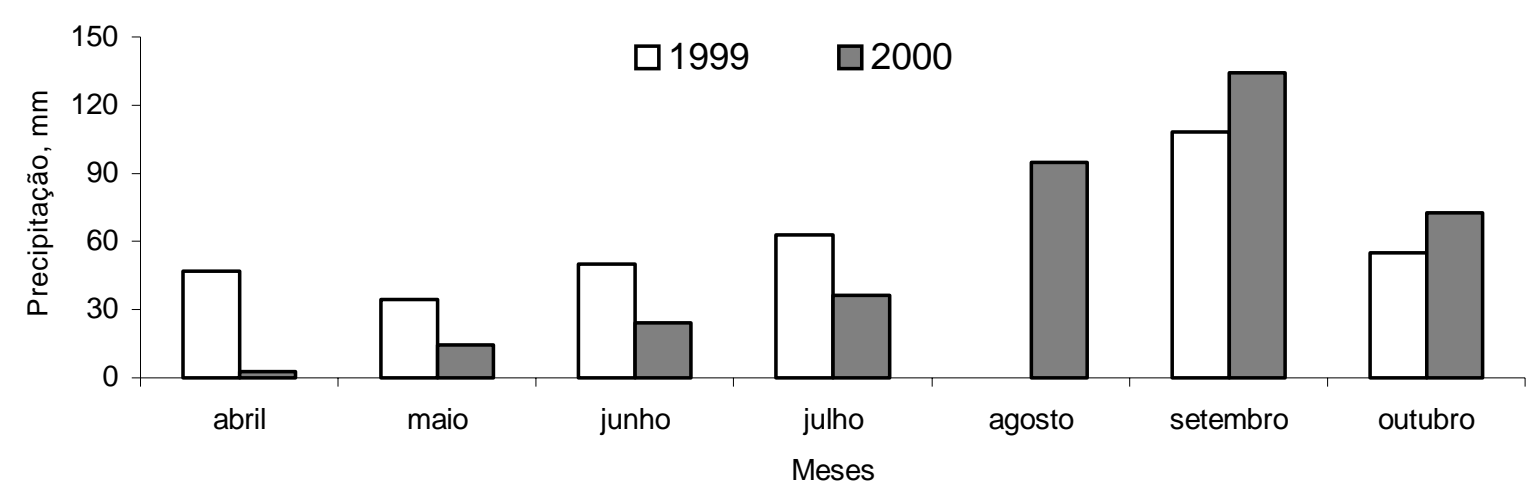

Figura 1. Precipitações pluviais mensais de abril a outubro no Pólo Regional de Desenvolvimento Tecnológico dos Agronegócios do Sudoeste Paulista, em Capão Bonito, em 1999 e 2000.

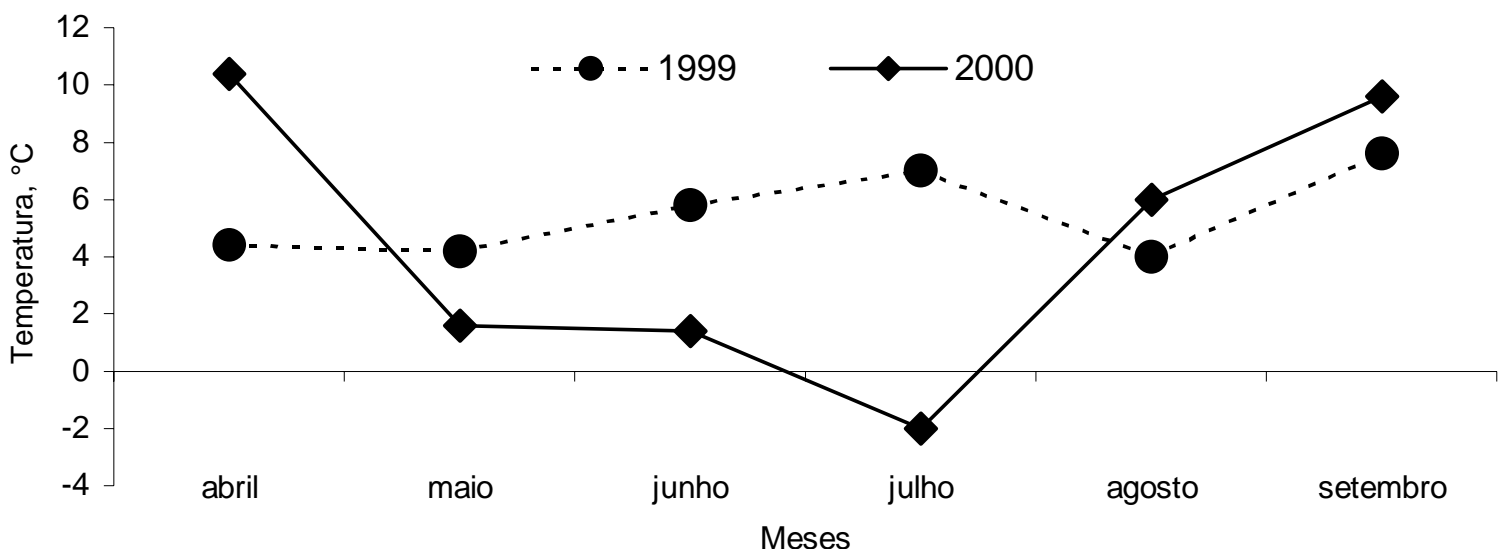

Figura 2. Temperaturas mínimas mensais de abril a setembro na Unidade de Pesquisa do Desenvolvimento de Tatuí, em 1999 e 2000.

A análise da variância conjunta dos experimentos de Tatuí, nos dois anos, mostrou efeitos significativos de genótipos e anos, indicando que a queda de 50,49\% no rendimento de 2000 foi devida às diferenças climáticas entre os dois anos, sobretudo com respeito às geadas de 2000 , durante o ciclo da cultura. Também a interação genótipos $\mathrm{x}$ anos foi significativa, mostrando que eles exibiram um comportamento diferente em relação aos anos em que foram avaliados.

Considerando-se as médias de produção de grãos dos experimentos de Tatuí, destacaram-se as linhagens 4 e 5 (3.267 e $\left.3.438 \mathrm{~kg} \cdot \mathrm{ha}^{-1}\right)$ como as mais produtivas, somente diferindo da $13\left(1.038 \mathrm{~kg} \cdot \mathrm{ha}^{-1}\right)$, a menos produtiva (Quadro 2). Em 1999, as linhagens 5 (4.583 kg.ha $\left.{ }^{-1}\right), 11$ (4.459 kg.ha $\left.{ }^{-1}\right)$ e $12\left(4.334\right.$ kg.ha $\left.{ }^{-1}\right)$ destacaram-se como as mais produtivas, diferindo, porém, em kg.ha ${ }^{-1}$, das linhagens 1 (2.201), 2 (2.222),
8 (2.722), 10 (1.799), 13 (1.445), 17 (1.924) e 18 (2.604), menos produtivas. No ano seguinte, destacou-se a linhagem 4 (2.417), não diferindo, pelo teste de Tukey a $5 \%$, em kg.ha ${ }^{-1}$, somente das linhagens 5 (2.292), 7 (2.326), 9 (2.139), 11 (1.785), 12 (1.771), 14 (1.694) e 18 (1.868).

No quadro 3, encontram-se os dados referentes à altura da planta avaliados em Capão Bonito e Tatuí, em ambos os anos. Considerando-se os experimentos de Capão Bonito, nos dois anos, a análise da variância mostrou efeitos significativos para genótipos e anos.

O fato de não haver interação genótipos $\mathrm{x}$ anos mostrou que, apesar das diferenças climáticas ocorridas entre os anos, os genótipos apresentaram, comparativamente, o mesmo comportamento, isto é, os mais altos em 1999 também tenderam ser os mais altos no ano seguinte. 
Quadro 2. Produção de grãos dos genótipos avaliados no Experimento de Linhagens Diaplóides de Trigo, instalado em Capão Bonito e Tatuí, em 1999 e 2000

\begin{tabular}{|c|c|c|c|c|c|c|}
\hline \multirow{3}{*}{ Genótipos } & \multicolumn{6}{|c|}{ Produção de grãos } \\
\hline & \multicolumn{3}{|c|}{ Capão Bonito } & \multicolumn{3}{|c|}{ Tatuí } \\
\hline & 1999 & 2000 & Média & 1999 & 2000 & Média \\
\hline & & 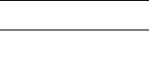 & 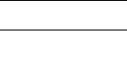 & & & \\
\hline 1 & $1232 \mathrm{~cd}$ & $490 \mathrm{c}-\mathrm{i}$ & 861 & $2201 \mathrm{~d}-\mathrm{g}$ & $1354 \mathrm{~d}-\mathrm{f}$ & $1778 \mathrm{ab}$ \\
\hline 2 & $1410 \mathrm{~b}-\mathrm{d}$ & $431 \mathrm{~d}-\mathrm{i}$ & 920 & $2222 \mathrm{c}-\mathrm{g}$ & 1549 b-e & $1885 \mathrm{ab}$ \\
\hline 3 & 1733 a-c & 931 a-c & 1332 & $3833 \mathrm{ab}$ & 1215 ef & $2524 a b$ \\
\hline 4 & 2021 a & $681 \mathrm{~b}-\mathrm{g}$ & 1351 & $4118 \mathrm{ab}$ & 2417 a & 3267 a \\
\hline 5 & 1778 a-c & $625 \mathrm{~b}-\mathrm{h}$ & 1201 & 4583 a & 2292 a-c & 3438 a \\
\hline 6 & $1865 \mathrm{ab}$ & 410 e-i & 1137 & 3583 a-d & $1410 \mathrm{~d}-\mathrm{f}$ & $2497 \mathrm{ab}$ \\
\hline 7 & 1674 a-c & $163 \mathrm{hi}$ & 918 & 3583 a-d & $2326 \mathrm{ab}$ & $2955 \mathrm{ab}$ \\
\hline 8 & 1768 a-c & $194 \mathrm{~g}-\mathrm{i}$ & 981 & $2722 \mathrm{~b}-\mathrm{g}$ & 1139 ef & $1931 \mathrm{ab}$ \\
\hline 9 & 1802 a-c & 1188 a & 1495 & 3472 a-e & 2139 a-d & $2806 \mathrm{ab}$ \\
\hline 10 & $969 \mathrm{~d}$ & 910 a-e & 939 & $1799 \mathrm{fg}$ & 1299 d-f & $1549 \mathrm{ab}$ \\
\hline 11 & 1625 a-c & $542 \mathrm{~b}-\mathrm{i}$ & 1083 & 4459 a & 1785 a-e & $3122 \mathrm{ab}$ \\
\hline 12 & 1861 a-c & $260 \mathrm{f}-\mathrm{i}$ & 1061 & 4334 a & 1771 a-e & $3052 \mathrm{ab}$ \\
\hline 13 & $976 \mathrm{~d}$ & $63 \mathrm{i}$ & 519 & $1445 \mathrm{~g}$ & $632 \mathrm{f}$ & $1038 \mathrm{~b}$ \\
\hline 14 & 1854 a-c & $288 \mathrm{f}-\mathrm{i}$ & 1071 & 3667 a-d & 1694 a-e & $2680 \mathrm{ab}$ \\
\hline 15 & $1292 b-d$ & 726 a-f & 1009 & 3695 a-c & 1340 d-e & $2517 \mathrm{ab}$ \\
\hline 16 & 1386 b-d & 726 a-f & 1056 & 3430 a-e & 1326 d-f & $2378 \mathrm{ab}$ \\
\hline 17 & 1688 a-c & $448 c-i$ & 1068 & 1924 e-g & $1438 \mathrm{c}-\mathrm{f}$ & $1681 \mathrm{ab}$ \\
\hline 18 & 1636 a-c & $993 \mathrm{ab}$ & 1314 & $2604 \mathrm{~b}-\mathrm{g}$ & 1868 a-e & $2236 \mathrm{ab}$ \\
\hline 19 & 1497 a-d & 792 a-e & 1144 & 3653 a-d & 1479 b-f & $2566 \mathrm{ab}$ \\
\hline 20 & 1660 a-c & $125 \mathrm{i}$ & 892 & 3229 a-f & 1493 b-f & $2361 \mathrm{ab}$ \\
\hline F (Genótipos) & $5,96^{*}$ & $11,24^{*}$ & 0,96 & $9,49^{*}$ & $7,48^{*}$ & $2,77^{*}$ \\
\hline F (Anos) & - & - & $113,35^{*}$ & - & - & $94,68^{*}$ \\
\hline$F(G \times A)$ & - & - & $7,53^{*}$ & - & - & $4,86^{*}$ \\
\hline d.m.s. ${ }^{(1)}$ & 629 & 497 & 1253 & 1579 & 857 & 2153 \\
\hline C.V. $(\%)$ & 15,10 & 34,49 & 21,03 & 18,63 & 20,43 & 19,91 \\
\hline
\end{tabular}

Médias seguidas de, pelo menos, uma letra comum não diferem, entre si, pelo teste de Tukey.

* Significativo a $5 \%$.

Comparando-se as médias dos experimentos de Capão Bonito, em 1999 e 2000, a linhagem 5 (78 $\mathrm{cm})$ exibiu as plantas mais altas, diferindo apenas, dos genótipos 13 e $20(49$ e $61 \mathrm{~cm})$. Quando se consideraram em conjunto os experimentos instalados em Tatuí, em 1999 e 2000, a análise da variância exibiu efeitos significativos para genótipos, para anos e para a interação genótipos $\mathrm{x}$ anos, indicando um comportamento diferenciado dos genótipos em relação aos anos de avaliação.
A linhagem $13(57 \mathrm{~cm})$ apresentou as plantas mais baixas, diferindo das demais pelo teste de Tukey a $5 \%$, quando se levou em conta o conjunto dos experimentos de Tatuí em ambos os anos. Em 1999, a linhagem $4(108 \mathrm{~cm})$ exibiu as plantas mais altas, não diferindo das linhagens $1,2,5,8,9,14$ e 16, com plantas de 100 a $107 \mathrm{~cm}$. Já em 2000, as linhagens 9 e 18 $(85 \mathrm{~cm})$ foram as mais altas, diferindo somente dos genótipos 3, 6, 10, 13, 17 e 19, com altura inferior a $70 \mathrm{~cm}$. 
Quadro 3. Altura da planta dos genótipos avaliados no Experimento de Linhagens Diaplóides de Trigo instalado em Capão Bonito e Tatuí em 1999 e 2000.

\begin{tabular}{|c|c|c|c|c|c|c|}
\hline \multirow{3}{*}{ Genótipos } & \multicolumn{6}{|c|}{ Altura da planta } \\
\hline & \multicolumn{3}{|c|}{ Capão Bonito } & \multicolumn{3}{|c|}{ Tatuí } \\
\hline & 1999 & 2000 & Média & 1999 & 2000 & Média \\
\hline & \multicolumn{6}{|c|}{$\mathrm{kg} \cdot \mathrm{ha}^{-1}$} \\
\hline 1 & $79 \mathrm{ab}$ & $61 \mathrm{ab}$ & $70 \mathrm{ab}$ & $100 \mathrm{a}-\mathrm{d}$ & $76 \mathrm{ab}$ & 88 a \\
\hline 2 & $79 \mathrm{ab}$ & $60 \mathrm{ab}$ & $69 \mathrm{ab}$ & 100 a-d & $78 \mathrm{ab}$ & 89 a \\
\hline 3 & $75 \mathrm{~b}$ & $65 a b$ & $70 \mathrm{ab}$ & 93 de & $69 \mathrm{~b}$ & $81 \mathrm{a}$ \\
\hline 4 & $81 \mathrm{ab}$ & 68 a & $74 \mathrm{ab}$ & 108 a & $77 \mathrm{ab}$ & $92 \mathrm{a}$ \\
\hline 5 & 88 a & $68 \mathrm{a}$ & $78 \mathrm{a}$ & 106 a-c & $80 \mathrm{ab}$ & 93 a \\
\hline 6 & $78 \mathrm{ab}$ & $61 \mathrm{ab}$ & $69 \mathrm{ab}$ & 98 c-e & $69 \mathrm{~b}$ & $83 \mathrm{a}$ \\
\hline 7 & $78 \mathrm{ab}$ & $55 \mathrm{a}-\mathrm{c}$ & $66 \mathrm{ab}$ & 93 de & $72 \mathrm{ab}$ & $83 \mathrm{a}$ \\
\hline 8 & $81 \mathrm{ab}$ & $63 \mathrm{ab}$ & $72 \mathrm{ab}$ & $107 \mathrm{ab}$ & $74 \mathrm{ab}$ & 90 a \\
\hline 9 & $81 \mathrm{ab}$ & $70 \mathrm{a}$ & $76 \mathrm{ab}$ & $107 \mathrm{ab}$ & 85 a & 96 a \\
\hline 10 & $75 \mathrm{~b}$ & $63 \mathrm{ab}$ & $69 \mathrm{ab}$ & 99 b-e & $66 \mathrm{bc}$ & 83 a \\
\hline 11 & $74 \mathrm{~b}$ & $61 \mathrm{ab}$ & $68 \mathrm{ab}$ & 93 de & $73 \mathrm{ab}$ & 83 a \\
\hline 12 & $81 \mathrm{ab}$ & $56 a-c$ & $69 \mathrm{ab}$ & $94 \mathrm{de}$ & $73 \mathrm{ab}$ & $83 \mathrm{a}$ \\
\hline 13 & $58 \mathrm{c}$ & $41 \mathrm{c}$ & $49 \mathrm{c}$ & $62 \mathrm{f}$ & $52 \mathrm{c}$ & $57 \mathrm{~b}$ \\
\hline 14 & $79 \mathrm{ab}$ & $61 \mathrm{ab}$ & $70 \mathrm{ab}$ & 106 a-c & $79 \mathrm{ab}$ & 93 a \\
\hline 15 & $78 \mathrm{ab}$ & $61 \mathrm{ab}$ & $69 \mathrm{ab}$ & 99 b-e & $74 \mathrm{ab}$ & 86 a \\
\hline 16 & $78 \mathrm{ab}$ & $63 \mathrm{ab}$ & $70 \mathrm{ab}$ & 100 a-d & $71 \mathrm{ab}$ & 85 a \\
\hline 17 & $81 \mathrm{ab}$ & $65 \mathrm{ab}$ & $73 \mathrm{ab}$ & 99 b-e & $68 \mathrm{~b}$ & $84 \mathrm{a}$ \\
\hline 18 & $74 \mathrm{~b}$ & $69 \mathrm{a}$ & $71 \mathrm{ab}$ & $94 \mathrm{de}$ & 85 a & 90 a \\
\hline 19 & $73 \mathrm{~b}$ & $68 \mathrm{a}$ & $70 \mathrm{ab}$ & $91 \mathrm{e}$ & $66 \mathrm{bc}$ & $78 \mathrm{a}$ \\
\hline 20 & $74 \mathrm{~b}$ & $48 \mathrm{bc}$ & $61 \mathrm{bc}$ & 92 de & $73 \mathrm{ab}$ & $82 \mathrm{a}$ \\
\hline F (Genótipos) & $5,88^{*}$ & $4,13^{*}$ & $4,34^{*}$ & $29,92^{*}$ & $6,50^{*}$ & $6,20^{*}$ \\
\hline F (Anos) & - & - & $159,79 *$ & - & - & $273,81^{*}$ \\
\hline$F(G \times A)$ & - & - & 1,76 & - & - & $3,11^{*}$ \\
\hline d.m.s. ${ }^{(1)}$ & 13 & 18 & 16 & 9 & 15 & 19 \\
\hline C.V. (\%) & 6,26 & 11,28 & 8,61 & 3,72 & 7,89 & 6,12 \\
\hline
\end{tabular}

Médias seguidas de, pelo menos, uma letra comum não diferem, entre si, pelo teste de Tukey.

* Significativo a $5 \%$

A correlação entre os dados médios de produção de grãos e a altura da planta, considerando-se as médias dos dois anos em cada local, mostrou-se positiva e significativa a $5 \%$ (Capão Bonito $\mathrm{r}=0,78^{*} \mathrm{e}$ Tatuí $\left.r=0,51^{*}\right)$, indicando a tendência de as plantas mais altas exibirem as maiores produções. Isso está de acordo com Camargo e Oliveira (1983), que estimaram a herdabilidade para várias características da planta e também a associação entre elas, a partir de cruzamentos entre a cultivar IAC-5, de porte alto, e 'Tordo', 'Vican-71' e 'Olesen', de plantas anãs. Esses dados, também, concordam com as investigações de CAMARGO (1987), que indicaram a associação entre produção de grãos e outras características agronômicas do trigo.
No quadro 4 encontram-se os dados de comprimento médio das raízes dos genótipos estudados e das cultivares-controle Anahuac e BH-1146, após 72 horas de crescimento em solução normal, que se seguiu a um crescimento em solução-tratamento contendo seis diferentes concentrações de alumínio, resultantes da média de cinco repetições.

Observou-se grande variabilidade no crescimento das raízes dos genótipos avaliados nas diferentes concentrações de alumínio.

Notou-se, ainda, tendência de diminuição do comprimento das raízes à medida que se aumentou a concentração de alumínio nas soluções (Quadro 4). 
Quadro 4. Comprimento médio das raízes dos genótipos avaliados no Experimento de Linhagens Diaplóides de Trigo, após 72 horas de crescimento em solução normal, que se seguiu a um crescimento em solução tratamento contendo seis concentrações de alumínio (média de cinco repetições)

\begin{tabular}{|c|c|c|c|c|c|c|}
\hline \multirow{2}{*}{ Genótipos } & \multicolumn{6}{|c|}{ Concentração de alumínio (mg.L $\left.{ }^{-1}\right)$} \\
\hline & 0 & 2 & 4 & 6 & 8 & 10 \\
\hline & & & 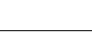 & . & & \\
\hline 1 & 57,5 & 17,6 & 6,1 & 1,5 & 0,4 & 0,3 \\
\hline 2 & 68,5 & 13,1 & 5,4 & 3,3 & 0,3 & 0,6 \\
\hline 3 & 61,8 & 36,4 & 26,9 & 17,4 & 15,9 & 11,2 \\
\hline 4 & 65,8 & 43,6 & 34,7 & 26,9 & 16,3 & 14,4 \\
\hline 5 & 63,3 & 40,9 & 32,6 & 25,6 & 16,4 & 13,2 \\
\hline 6 & 60,2 & 40,8 & 32,5 & 18,9 & 12,3 & 10,1 \\
\hline 7 & 69,5 & 39,5 & 21,9 & 8,0 & 4,7 & 1,8 \\
\hline 8 & 68,5 & 43,0 & 25,6 & 17,4 & 15,5 & 5,0 \\
\hline 9 & 66,9 & 43,0 & 26,3 & 19,4 & 11,5 & 8,0 \\
\hline 10 & 66,9 & 40,1 & 26,5 & 19,9 & 9,9 & 10,1 \\
\hline 11 & 73,7 & 40,5 & 24,8 & 18,0 & 14,7 & 9,6 \\
\hline 12 & 71,3 & 40,4 & 21,9 & 24,4 & 14,0 & 10,1 \\
\hline 13 & 61,1 & 6,1 & 3,3 & 0,7 & 0,0 & 0,0 \\
\hline 14 & 74,0 & 58,0 & 16,4 & 13,3 & 12,2 & 7,2 \\
\hline 15 & 66,5 & 16,6 & 9,0 & 5,0 & 3,1 & 4,6 \\
\hline 16 & 81,9 & 51,0 & 23,2 & 14,5 & 11,6 & 7,9 \\
\hline 17 & 62,4 & 41,8 & 18,1 & 8,7 & 10,5 & 7,4 \\
\hline 18 & 73,6 & 40,9 & 22,2 & 18,4 & 16,1 & 11,6 \\
\hline 19 & 77,7 & 50,7 & 44,0 & 34,3 & 24,2 & 19,5 \\
\hline 20 & 81,5 & 28,8 & 6,9 & 0,0 & 0,0 & 0,0 \\
\hline ВН-1146 & 90,7 & 75,3 & 55,1 & 44,8 & 23,4 & 12,6 \\
\hline Anahuac & 87,6 & 0,0 & 0,0 & 0,0 & 0,0 & 0,0 \\
\hline
\end{tabular}

Em solução nutritiva com ausência de alumínio, todos os genótipos apresentaram crescimento normal das raízes e a diferença verificada entre o comprimento das raízes dos genótipos avaliados nessa condição deveu-se à constituição genética de cada um.

Nas soluções contendo 2 e $4 \mathrm{mg} \cdot \mathrm{L}^{-1}$, apenas a cultivar Anahuac apresentou paralisação irreversível do meristema da raiz primária central, sendo considerada suscetível. A sensibilidade da cultivar a essas concentrações já foi relatada por CAMARGO et al. (1998). Nos demais genótipos, observou-se redução de crescimento, mostrando tolerância a essas concentrações.

Os genótipos 20 (IAC-289) e 13 apresentaram paralisação do crescimento da raiz após tratamento com solução contendo 6 e $8 \mathrm{mg} . \mathrm{L}^{-1}$, respectivamente, sendo considerados sensíveis a tais concentrações. Os demais genótipos revelaram-se tolerantes por apre- sentarem crescimento de raízes após tratamento nessas concentrações. Na concentração contendo 10 $\mathrm{mg} . \mathrm{L}^{-1}$, todos os genótipos apresentaram crescimento de raízes, sendo considerados tolerantes a essa concentração, exceto 13 e 20 e a cultivar Anahuac.

Nos experimentos instalados em Tatuí, em solo ácido com aplicação de calcário e com irrigação por aspersão, as raízes dos genótipos foram mantidas em quase sua totalidade na camada arável. Esse fato impediu que a provável presença de alumínio no subsolo representasse um fator de limitação para o desenvolvimento dos genótipos avaliados.

Nos experimentos instalados em Capão Bonito, em condição de sequeiro e solo ácido sem aplicação de calcário, a presença de alumínio na camada arável prejudicou o desenvolvimento dos genótipos, como se pode observar comparando-se as produções dos dois locais em 1999. 
Nesse ano, as condições climáticas não foram tão adversas quanto às do ano seguinte (Figuras $1 \mathrm{e}$ 2). A correlação entre as médias de produção de grãos de cada genótipo e o comprimento médio das raízes em cada concentração de alumínio, considerando-se em conjunto os dois anos, em cada local separadamente, apresentaram resultados significativos e positivos (Quadro 5) para todas as concentrações, exceto para a ausência de alumínio, mostrando uma relação significativa entre os resultados em solução nutritiva e aqueles no campo. Esses resultados concordam com aqueles de CAMARgO e Oliveira (1981).

Quadro 5. Correlação simples entre rendimento e comprimento da raiz nas diferentes concentrações de $\mathrm{Al}^{3+}$

\begin{tabular}{ccc}
\hline $\begin{array}{c}\text { Concentração } \\
\text { de } \mathrm{Al}^{3+}\end{array}$ & $\begin{array}{c}\text { Capão Bonito } \\
1999-2000\end{array}$ & $\begin{array}{c}\text { Tatuí } \\
1999-2000\end{array}$ \\
\hline 0 & $-0,08$ & 0,10 \\
2 & $0,56^{*}$ & $0,48^{*}$ \\
4 & $0,54^{*}$ & $0,46^{*}$ \\
6 & $0,61^{*}$ & $0,55^{*}$ \\
8 & $0,67^{*}$ & $0,53^{*}$ \\
10 & $0,60^{*}$ & $0,44^{*}$ \\
\hline
\end{tabular}

A correlação entre as médias de altura da planta de cada genótipo e o comprimento médio das raízes em cada concentração de alumínio, considerando-se em conjunto os dois anos, apresentaram resultados significativos e positivos, apenas para os dados de Capão Bonito (Quadro 6), para todas as concentrações, exceto para a ausência de alumínio, mostrando uma relação significativa entre os resultados em solução nutritiva e aqueles no campo.

Quadro 6. Correlação simples entre a altura da planta e o comprimento da raiz nas diferentes concentrações de $\mathrm{Al}^{3+}$

\begin{tabular}{ccc}
\hline $\begin{array}{c}\text { Concentração } \\
\text { de } \mathrm{Al}^{3+}\end{array}$ & $\begin{array}{c}\text { Capão Bonito } \\
1999-2000\end{array}$ & $\begin{array}{c}\text { Tatuí } \\
1999-2000\end{array}$ \\
\hline 0 & $-0,02$ & 0,19 \\
2 & $0,49^{*}$ & 0,34 \\
4 & $0,44^{*}$ & 0,16 \\
6 & $0,48^{*}$ & 0,22 \\
8 & $0,54^{*}$ & 0,24 \\
10 & $0,53^{*}$ & 0,24 \\
\hline
\end{tabular}

A obtenção de linhagens diaplóides a partir da duplicação cromossômica de plantas haplóides, em geração $F_{1}$, foi altamente eficiente para originar novos genótipos de trigo com características agronômicas vantajosas ao programa de melhoramento tradicional, confirmando trabalhos publicados (CAMARGO et al., 1999; RAMOS et al., 2000; SALOMON et al., 2003).

\section{CONCLUSÕES}

1. As linhagens diaplóides consideradas mostraram grande variabilidade para os caracteres agronômicos avaliados.

2. Destacaram-se quanto à produção de grãos, em Capão Bonito, em solo ácido e condição de sequeiro, as linhagens 3, 4 e 9. Em Tatuí, em solo com aplicação de calcário e condição de irrigação por aspersão, as linhagens 4 e 5 .

3. A linhagem 13 apresentou as plantas mais baixas independentemente dos locais e anos em que foi avaliada.

4. Ficou evidenciada a possibilidade de selecionar os genótipos tolerantes ao alumínio em condição de laboratório antes que sejam avaliados no campo, em solo ácido, tornando o processo de obtenção de linhagens tolerantes mais eficiente.

5. Na concentração contendo $10 \mathrm{mg} \cdot \mathrm{L}^{-1}$, todos os genótipos apresentaram crescimento de raízes, sendo considerados tolerantes a essa concentração, exceto os genótipos 13 e 20 e a cultivar Anahuac.

\section{REFERÊNCIAS BIBLIOGRÁFICAS}

ALVES, V.M.C.; NOVAIS, R.F.; NEVES, J.C.L.; BARROS, N.F. Efeito do alumínio sobre a absorção e translocação de fósforo e sobre a composição mineral de duas cultivares de trigo. Pesquisa Agropecuária Brasileira, Brasília, v.23, n.6, p.563-573, 1988.

BRAUNER, J.L.; SARRUGE, J.R. Tolerância de cultivares de trigo (Triticum aestioum L.) ao alumínio e ao manganês. I. Determinação da tolerância ao alumínio. Anais da Escola Superior de Agricultura "Luiz de Queiroz", Piracicaba, v.37, n.2, p.805824, 1980.

CAETANO, V.R.; MORAES-FERNANDES, M.I.B. Interdisciplinaridade no CNPT/EMBRAPA: estudos que culminaram com o lançamento, por meio de métodos biotecnológicos, do trigo BR-43. In: ENCONTRO DE GENETICISTAS DO RIO GRANDE DO SUL, 8., 1992, São Leopoldo. Anais... São Leopoldo: SBG, 1992. p.15-19. 
CAMARGO, C.E.O.. Melhoramento do trigo: XIII. Estimativas de variância, herdabilidade e correlações em cruzamentos de trio para a produção de grãos e tolerância à toxicidade de alumínio. Bragantia, Campinas, v.46, n.1, p.73-89, 1987.

CAMARGO, C.E.O.; OLIVEIRA, O.F. de. Tolerância de cultivares de trigo a diferentes níveis de alumínio em solução nutritiva e no solo. Bragantia, Campinas, v.40, n.1, p.21-31, 1981.

CAMARGO, C.E.O.; OLIVEIRA, O.F. Melhoramento do trigo: V. Estimativa da herdabilidade e correlações entre altura de planta, produção de grãos e outros caracteres agronômicos em trigo. Bragantia, Campinas, v.42, p.131-148, 1983.

CAMARGO, C.E.O.; FELÍCIO, J.C.; FERREIRA FILHO, A.W.P.; FREITAS, J.G.; BARROS, B.C.; CASTRO, J.L.; SABINO, J.C.; KANTHACK, R.A.D. Melhoramento do trigo: XXIII. Avaliação de linhagens na região do Vale do Paranapanema, em Capão Bonito e em Tietê, em 1984-88. Bragantia, Campinas, v.49, n.1, p.43-67, 1990.

CAMARGO, C.E.O.; FELÍCIO, J.C.; FERREIRA FILHO, A.W.P.; BARROS, B.C.; FREITAS, J.G. de; PETTINELLI JÚNIOR, A.; GALLO, P.B.; KANTHACK, R.A.D. Melhoramento do trigo: XXV. Avaliação de genótipos oriundos de populações híbridas introduzidas de Oregon (EUA) no Estado de São Paulo. Bragantia, Campinas, v.50, n.2, p.225-246, 1991a.

CAMARGO, C.E.O.; FELÍCIO, J.C.; FERREIRA FILHO, A.W.P.; FREITAS, J.G.; KANTHACK, R.A.D.; BARROS, B.C. Melhoramento de trigo: XXIV. Avaliação de novos genótipos no Estado de São Paulo. Bragantia, Campinas, v.50, n.2, p.203-223, 1991 b.

CAMARGO, C.E.O.; FERREIRA FILHO, A.W. P; FELÍCIO, J.C. Herdabilidade e correlações entre características agronômicas em populações híbridas de trigo. Bragantia, Campinas, v.57, n.1, p.95-104, 1998.

CAMARGO, C.E.O.; RAMOS, L.C.S.; FERREIRA FILHO, A.W.P.; FELÍCIO, J.C.; PETTINELLI JR., A.; CASTRO, J.L.; YOKOO, E.Y. Linhagens diaplóides de trigo: produção de grãos, características agronômicas e tolerância à toxicidade de alumínio. Bragantia, Campinas, v.58, p.235-246, 1999.

CAMPINAS, INSTITUTO AGRONÔMICO. Recomendações da Comissão Técnica de Trigo para 1999. 2.ed. Campinas, 1999. 100p. (Boletim Técnico IAC, 167).
CAMPINAS, INSTITUTO AGRONÔMICO. Recomendações da Comissão Técnica de Trigo para 2002. 3.ed.atual. Campinas: Instituto Agronômico, 2002. 92p. (Série Tecnológica APTA, Boletim Técnico IAC, 167).

CAMPINAS, INSTITUTO AGRONÔMICO. Reunião da Comissão Técnica de Trigo da Secretaria de Agricultura e Abastecimento do Estado de São Paulo: Variedades de trigo para o Estado de São Paulo. Campinas, 1996. 20p. (IAC, Boletim Técnico, 163).

MORAES-FERNANDES, M.I.B.;STIVAL, A.L.; BRAMMER, S.P., et al. Haplodiploidização: genética e melhoramento. In: TORRES, A.C.; CALDAS, L.S., BUSO, J.A. Cultura de tecidos e transformação genética de plantas. Brasília : EMBRAPA/CBAB, 1999. v.2, p.569-612.

MOTA, F.S. Clima e zoneamento para a triticultura no Brasil. In: FUNDAÇÃO CARGILL. Trigo no Brasil. Campinas, 1982. v. 2, p.29-64.

OLMOS, J.I.L.; CAMARGO, M.N. Ocorrência de alumínio tóxico nos solos do Brasil, sua caracterização e distribuição. Ciência e Cultura, Rio de Janeiro, v.28, n.2, p.171-180, 1976.

RAIJ, B. van.; SILVA, N.M.; BATAGLIA, O.C.; QUAGGIO, J.A.; HIROCE, R.; CANTARELLA, H.; BELINAZZI JUNIOR, R.; DECHEN, A.R.; TRANI, P.E. Recomendações de adubação e calagem para o Estado de São Paulo. Campinas: Instituto Agronômico, 1985. 107p. (Boletim Técnico IAC, 100)

RAMOS, L.C.S.; YOKOO, Y.; CAMARGO, C.E.O. Cultura de anteras de trigo. I. Adequação de meios de cultura e testes de genótipos. Bragantia, Campinas. v.53, n.2, p.151-157, 1994.

RAMOS, L.C.S.; CAMARGO, C.E.O.; FERREIRA FILHO, A.W.P.; YOKOO, E.Y.; CASTRO, J.L.; PETTINELLI JR., A.; SILVA, M.R. da. Melhoramento do trigo: avaliação de linhagens diaplóides obtidas via cultura de anteras. Scientia Agricola, Piracicaba, v.57, p.177-183, 2000.

ROSA, O.S.; CAMARGO, C.E.O.; RAJARAM, S.; ZANATA, A.C.A. Produtividade de trigo (Triticum aestivum (L.) Thell) com tolerância ao alumínio tóxico no solo. Pesquisa Agropecuária Brasileira, Brasília, v.29, n.3, p.411-417, 1994.

SALOMON, M.V.; CAMARGO, C.E.O.; PETTINELLI JR., A.; AZEVEDO FILHO, J.A. Performance of dihaploid wheat lines obtained via anther culture. Scientia Agrícola, Piracicaba, v.60, n.1, p.43-50, 2003. 